\title{
Resistant starch prevents tumorigenesis of dimethylhydrazine-induced colon tumors via regulation of an ER stress-mediated mitochondrial apoptosis pathway
}

\author{
QIUYU WANG, PENG WANG and ZHIGANG XIAO \\ College of Food Science, Northeast Agricultural University, Harbin, Heilongjiang 150030, P.R. China
}

Received November 28, 2016; Accepted January 12, 2018

DOI: $10.3892 /$ ijmm.2018.3423

\begin{abstract}
Resistant starch is as common soluble fiber that escapes digestion in the small intestine and can regulate intestinal function, metabolism of blood glucose and lipids, and may prevent tumorigenesis of gastrointestinal cancer. Epidemiology and other evidence have suggested that resistant starch may prevent colon cancer development. The aim of the current study was to explore the ameliorative effects and potential mechanisms of resistant starch in the tumorigenesis of colon tumors induced by dimethylhydrazine in C57BL/6 mice. Western blot analysis, ELISA, microscopy, immunofluorescence and immunohistochemistry were used to analyze the efficacy of resistant starch on the metabolic balance in the colon and tumorigenesis of colon tumors. The results demonstrated that a diet containing resistant starch decreased the animal body weight and reduced free ammonia, $\mathrm{pH}$ and short chain fatty acids in feces compared with mice that received a standard diet. Resistant starch reduced the incidence of colon tumors and suppressed the expression of carcinogenesis-associated proteins, including heat shock protein 25 , protein kinase $\mathrm{C}$-d and gastrointestinal glutathione peroxidase in colon epithelial cells compared with standard starch and control groups. Colon tumor cells proliferation and dedifferentiation were significantly decreased by a resistant starch diet. The results also demonstrated that resistant starch increased the apoptosis of colon tumor cells through regulation of apoptosis-associated gene expression levels in colon tumor cells. Oxidative stress and endoplasmic reticulum stress were upregulated, and elevation eukaryotic translation initiation factor $2 \alpha$ (eIF2 $\alpha$ ), activating transcription factor- 4 and secretase- $\beta$ expression levels were increased in the resistant starch diet group. Additionally, the activity of eIF $2 \alpha$ and PERK were increased in colon tumor cells from mice that had received resistant starch. Increasing DNA damage-inducible transcript 3 protein $(\mathrm{CHOP})$, binding immunoglobulin protein (BIP) and
\end{abstract}

Correspondence to: Professor Zhigang Xiao, College of Food Science, Northeast Agricultural University, 59 Mucai Street, Xiangfang, Harbin, Heilongjiang 150030, P.R. China

E-mail: xiaozhigangprof@163.com

Key words: resistant starch, tumorigenesis, colon tumor, apoptosis, endoplasmic reticulum stress caspase-12 expression levels upregulated by resistant starch diet may contribute to the resistant starch-induced apoptosis of colon tumor cells induced by 1,2-dimethylhydrazine. In vitro assays demonstrated that knockdown of eIF $2 \alpha$ inhibited apoptosis of colon tumor cells isolated from mice fed with resistant starch, which also downregulated CHOP, BIP and caspase-3 expression levels compared with controls. Furthermore, long-term survival of experimental mice was prolonged by the resistant starch diet compared with the standard diet group. In conclusion, the results indicate that resistant starch in the diet may prevent carcinogenesis of colon epithelial cells, mediated by enhancing apoptosis through an endoplasmic reticulum stress-mediated mitochondrial apoptosis pathway.

\section{Introduction}

Colon cancer is one of the most common gastrointestinal tumors; it is the second most common cancer in women and third in men worldwide (1). In recent years, diagnosis, treatments and prognosis of patients with colon cancer have been improved (2). Systematic review has provided various targeted therapies for the treatment of advanced colorectal cancer and explored the potential of predictive biomarkers (3). However, no satisfactory therapies for colon cancer have been developed clinically due to local migration and long distance metastasis (4). Colon cancer metastasis and invasion is a major issue for clinicians and detrimental for patients with colon cancer $(5,6)$. The underlying molecular mechanisms of colorectal cancer metastasis and invasion have attracted research to develop targeted therapies for suppressing metastasis and invasion (7-9). Given that regulation of tumor cell growth and metastasis is imperative for patients with colon cancer and for future development of clinical strategies, molecular bioinformatics has enabled biopharmaceutical researchers to screen for targeted molecules that could be useful for diagnosis and therapy protocols, and offer the possibility of individual tailored medicine for patients with cancer or other human diseases $(10,11)$.

Resistant starch is widely present in carbohydrate starch material and has miscellaneous effects in colon metabolism (12). The structure-physiological function of resistant starch is associated with the extent of digestion and absorption in the colon (13). Systematic review and meta-analysis of randomized controlled trials have demonstrated the beneficial effects of resistant starch supplementation on bowel function in healthy adults by increasing fecal wet weight, butyrate concentration, 
fecal $\mathrm{pH}$ and defecation frequency (14). Dronamraju et al (15) investigated the effects of resistant starch on cell kinetics and gene expression changes in patients with colorectal cancer given resistant starch in a randomized controlled trial (15). Studies have suggested that dynbiotic intervention of Bifidobacterium lactis and resistant starch are protective against colorectal cancer development in a rat-azoxymethane model, and long-term consumption of resistant starch markedly decreased the risk of colorectal cancer in a randomized controlled trial $(16,17)$.

Increasing apoptosis of tumors cells has benefits for prevention and treatment of colon cancer through regulation of the expression of apoptosis-associated proteins (18). It has been reported that endoplasmic reticulum (ER) stress is associated with apoptosis of colon cancer cells (19). A previous study has reported that upregulation of the ER stress pathway can reduce $\gamma$-tocotrienol-induced apoptosis in mammary tumor cells (20). Edagawa et al (21) investigated the function of activating transcription factor-3 (ATF-3) in ER stress-induced apoptosis in human colon cancer cells. These studies indicated that ER stress-mediated apoptosis may be associated with tumorigenesis and development of colon cancer.

The current study investigated the anticancer effects and potential mechanisms of resistant starch in the tumorigenesis, formation and development 1,2-dimethylhydrazine-induced colon cancer. The colon physiological functions of experimental mice were analyzed following consumption of a diet containing resistant starch. Notably, this analysis investigated whether resistant starch induces apoptosis of colon tumor cells following treatment with 1,2-dimethylhydrazine.

\section{Materials and methods}

Ethics statement. This study was performed in strict accordance with the recommendations in the Guide for the Care and Use of Laboratory Animals (22). All experimental protocols were performed in accordance with National Institutes of Health and approved by the Committee on the Ethics of Animal Experiments Defence Research (Northeast Agricultural University, Harbin, China).

Animal study. A total of 20 C57BL/6 mice, 6-8 weeks old, were purchased from Jackson Laboratory (Bar Harbor, ME, USA) and housed in a temperature-controlled room $\left(25 \pm 1^{\circ} \mathrm{C}\right)$ with artificial 12/12 h light/dark cycle. All mice could access water containing 1,2-dimethylhydrazine ( $3 \mathrm{mg} / \mathrm{kg}$ ) to induce colon cancer. The incidence of colon tumor induced by 1,2-dimethylhydrazine was calculated by histopathology as described in immunohistochemistry assay. Experimental mice were divided into two groups ( $n=10 /$ group) with free access to a regular diet $(5 \mathrm{mg} / \mathrm{kg})$ or a resistant starch diet $(5 \mathrm{mg} / \mathrm{kg})$. All mice were sacrificed for further analysis on day 120 .

Analysis of ammonia, pH and short chain fatty acids. Ammonia in experimental mice was measured using ionization constant. $\mathrm{pH}$ was determined by $\mathrm{pH}$ meter (Mettler). Short chain fatty acids were analyzed using High Performance Liquid Chromatography (Takara, Tokyo, Japan).

Cells culture and reagents. Colon epithelial cells and colon tumor cells were isolated from experimental mice and cultured in Dulbecco's modified Eagle's medium (DMEM) supplemented with 10\% fetal bovine serum (FBS; Sigma-Aldrich; Merck KgaA, Darmstadt, Germany). Cells were cultured at $37^{\circ} \mathrm{C}$ and $5 \% \mathrm{CO}_{2}$.

Reverse transcription-quantitative polymerase chain reaction $(R T-q P C R)$. RNA was reverse transcribed into cDNA at $42^{\circ} \mathrm{C}$ for $2 \mathrm{~h}$ using the High Capacity cDNA Reverse Transcription kit (Thermo Fisher Scientific, Inc., Waltham, MA, USA) according to the manufacturer's protocol. PCR amplification had preliminary denaturation at $94^{\circ} \mathrm{C}$ for $2 \mathrm{~min}$, followed by 45 cycles of $95^{\circ} \mathrm{C}$ for $30 \mathrm{sec}$; the annealing temperature was reduced to $56.8^{\circ} \mathrm{C}$ for $30 \mathrm{sec}$ and $72^{\circ} \mathrm{C}$ for $10 \mathrm{~min}$. The reaction volume was a total of $20 \mu \mathrm{l}$ containing $50 \mathrm{ng}$ genomic cDNA, $200 \mu \mathrm{M}$ dNTPs, $200 \mu \mathrm{M}$ primers, and Taq DNA polymerase and SYBRGreen (both 2.5 U; Thermo Fisher Scientific, Inc.). Total RNA was extracted from colon epithelial cell and colon tumor cells by using RNAeasy mini kit (Qiagen, Inc., Valencia, CA, USA). mRNA expression levels of heat shock protein 25 (HSP25), protein kinase C-d (PKC-d), gastrointestinal glutathione peroxidase (GI-GPx), c-myc, Ras, p53, proliferating cell nuclear antigen (PCNA), claudin 1, claudin 2, mechanistic target of rapamycin kinase (mTOR), hexokinase-2 (HK-II), caspase-3, caspase-9, p53, Bcl-2 apoptosis regulator (Bcl-2), superoxide dismutase (SOD) and glutathione synthetase (GSH) in colon epithelial cell and/or colon tumor cells were measured by RT-qPCR with $\beta$-actin as an endogenous control (23) (Invitrogen; Thermo Fisher Scientific, Inc.). All the forward and reverse primers were synthesized by Invitrogen (Thermo Fisher Scientific, Inc.) (Table I). Relative mRNA expression changes were calculated by $2^{-\Delta \Delta \mathrm{Cq}}(24)$. The results are expressed as the $n$-fold change compared with control.

Western blot analysis. Colon tumor cells were homogenized in a radioimmunoprecipitation assay buffer (Sigma-Aldrich; Merck KgaA) and centrifuged at $6,000 \mathrm{x} \mathrm{g}$ at $4^{\circ} \mathrm{C}$ for $10 \mathrm{~min}$. Protein concentration was measured with a bicinchoninic acid protein assay kit (Thermo Fisher Scientific, Inc.). A total of $10 \mu \mathrm{g} /$ lane protein was were separated in a $12 \%$ SDS assay and then transferred onto polyvinylidene fluoride membranes (EMD Millipore, Billierica, MA, USA). Membranes were blocked in 5\% BSA (Sigma-Aldrich; Merck KgaA) for $1 \mathrm{~h}$ at $37^{\circ} \mathrm{C}$ and subsequently incubated with the following primary antibodies: HSP25 (ab202846), PKC-d (ab182126), GI-GPX (ab137431), c-myc (ab32071), Ras (ab52939), P53 (ab1431), PCNA (ab18197), claudin1 (ab15098), claudin2 (ab53032), mTOR (ab2732) and HK-II (ab24937), caspase-3 (ab13847), caspase-9 (ab202068), Bcl-2 (ab59348), SOD (ab13533), GSH (ab26255), DDIT3 (ab179823) , Beclin1 (ab62557), CHOP (ab10444), BIP (ab108615), caspase-12 (ab62484), ATF-4 (ab23760), BACE1 (ab2077), eIF2 $\alpha$ (ab5369) and $\beta$-actin (ab8227) for $12 \mathrm{~h}$ at $4^{\circ} \mathrm{C}$. All primary antibodies were used at a dilution of 1:1,000 and purchased from Abcam (Cambridge, UK). The membranes were then incubated with horseradish peroxidase (HRP)-conjugated goat anti-rabbit immunoglobulin G ( $\mathrm{IgG}$ ) monoclonal secondary antibodies (1:2,000; cat. no. PV-6001; OriGene Technologies, Inc., Beijing, China) for $24 \mathrm{~h}$ at $4^{\circ} \mathrm{C}$. An enhanced chemiluminescence substrate ECL Select ${ }^{\mathrm{TM}}$ (Roche Diagnostics, Basel, Switzerland) was used to analyze the protein expression (Olympus BX51; Olympus Corporation, Tokyo, Japan). 
Table I. Primer sequences for RT-qPCR.

Gene name

Sequences

\section{HSP25}

F: 5'-ATCGAGATCTAATGGAGCCAGGGGAGGCG-3'

R: 5'-ATCGAGATCTGGAGAAGGCGGAGGGCGCGG-3'

PKC-d

Forward: 5'-GCATCCTCTTCAGTTACGTCC -3'

Reverse: 5'-AAGAGAGCTTCCGTAAGGCG-3'

GI-GPX

Forward: 5'-GAGGATATTTCGTGCCGCGC -3'

Reverse: 5'-GGAAGCTCCTGAAGATCTGT-3'

c-myc

Forward: 5'-ATTGGGACAGCTTGGATCAC-3'

Reverse: 5'-AGTCACACGTCATCGACACC-3'

Ras

Forward: 5'-CGCATCCTCAAAGGAGACATTCC-3'

Reverse: 5'-CACATCGAGGTGAACGGGAGTAAG-3'

p53

Forward: 5'-AAGGATCCTCAGTCTGAGTCAGGCC-3'

Reverse: 5'-ACCACCATCCACTACAACTAC-3'

PCNA

Forward: 5'-AGCACGGTAACGTAGGGTGT-3'

Reverse: 5'-CATTGGAGGCATAAGCTG-3'

Claudin1

Forward: 5'-AGAACCAGTGAGCCTGATACATACAG-3'

Reverse: 5'-GCAACTCCATCGGCCTTTCCTACCAG-3'

Claudin2

Forward: 5'-GGAGTAGAAGTCCCGCAGGAT-3'

Reverse: 5'-AGGCCTCCTGGGCTTCAT-3'

m-TOR

Forward: 5'-CGTACATGTCAGCCAGCTTC-3'

Reverse: 5'-TGGAGGAATTCTTGCTTTGC-3'

HK

Forward: 5'-GACGCAATCAATGTTTACTCG-3'

Reverse: 5'-TATTTGGTTGGTCAGCACAGG-3'

Caspase-3

Forward: 5'-TTGAGGTAGCTGCACTGTGG-3'

Reverse: 5'-GGGCGTGTTTCTGTTTTGTT-3'

Caspase-9

Forward: 5'-CCAACCAAATGAAGCCAAGT-3'

Reverse: 5'-GCCCTTGCCTCTGAGTAGTG-3'

CPI

Forward: 5'-GGAACACCTCGCTCTCCA-3'

Reverse: 5'-GGGATTCCCTGGACCTAAAG-3'

Bcl-2

Forward: 5'-CGTCTTCAGAGACAGCCAGGAG-3'

Reverse: 5'-TGAACCGGCATCTGCACAC-3'

SOD

Forward: 5'-TTTGCCAGCAGTCACATTGC-3'

Reverse: 5'-GTACCAGTGCAGGTCCTCAC-3' GSH

Forward: 5'-CCGATCCAATCTGTTCTGGT-3'

Reverse: 5'-CCAGGGCTTTTCAAAAATGA-3'

$\beta$-actin

Forward: 5'-AGCCTTCTCCATGGTCGTGA-3'

Reverse: 5'-CGGAGTCAACGGATTTGGTC-3'
Transfection of small interfering RNA (siRNA). Colon tumor cells $\left(1 \times 10^{6}\right)$ were transfected with 100 pmol of siRNA targeting eukaryotic translation initiation factor $2 \alpha$ (eIF2 $\alpha$ ) with siRNA-vector as control (both from Applied Biosystems; Thermo Fisher Scientific, Inc.) using a Cell Line Nucleofector kit L. (Lonza Group, Ltd., Basel, Switzerland). Cells were cultured in $2.5 \mathrm{ml}$ DMEM containing 10\% FBS 6-well plates for $24 \mathrm{~h}$. All siRNAs were synthesized by Invitrogen (Thermo Fisher Scientific, Inc.) including siRNA-eIF $2 \alpha$ (eIF $2 \alpha$, L-015389) or siRNA-vector (scramble, D-001810). Cells were used for the subsequent assays after 48-h transfection.

Cell differentiation. Colon tumor cells isolated from experimental mice and cultured in Dulbecco's modified Eagle's medium (DMEM) supplemented with $10 \%$ fetal bovine serum (FBS; Sigma-Aldrich; Merck KgaA) at a $37^{\circ} \mathrm{C}$ humidified atmosphere of $5 \% \mathrm{CO}_{2}$. Cell colonies growing on Matrigel ${ }^{\circledR}$ were loosely detached by dispase treatment for $5 \mathrm{~min}$, washed 3 times with PBS. Cells were resuspended in DMEM medium containing 20\% FBS. Cells were maintained on $1 \%$ agar-coated and allowed to differentiate for another 18 days. Cells were then fixed with $10 \%$ formalin for $1 \mathrm{~h}$ at $37^{\circ} \mathrm{C}$. Next following stained with the $60 \%$ Oil Red O in isopropanol as working solution for $10 \mathrm{~min}$. The proportion of Oil Red O-positive cells was determined by counting stained cells under a light microscope.

Activity assays. Eukaryotic translation initiation factor 2- $\alpha$ kinase 3 (PERK) activity in colon tumor cells was analyzed by recombinant glutathione S-transferase-PERK (536-1,116 amino acids) with 6-His-full-length human eIF2 $\alpha$ as a substrate (25). eIF2 $\alpha$ activity was analyzed by stimulation of eIF-2- $\alpha$ kinase GCN2 in colon tumor cells (26). AMPK activity was determined by transient transfection assays as described previously (27).

Immunohistochemistry and immunofluorescent staining. Immunohistochemistry and immunofluorescent staining were performed according to the standard procedures (28). Paraffin-embedded colon tumor tissues sections were prepared and epitope retrieval was performed for further analysis. The paraffin sections were treated with hydrogen peroxide $(3 \%)$ for 10-15 min, which subsequently blocked by a regular blocking solution for $10-15 \mathrm{~min} 37^{\circ} \mathrm{C}$ for immunohistochemistry. Colon tumor cells were cultured and stained with microtubule associated protein 1 light chain $3 \alpha$ (MAP1LC3A), translocase of outer mitochondrial membrane 20 (TOMM20) for observation of microtubules and/or microvessels, Neo (Nase), and calreticulin (Invitrogen; Thermo Fisher Scientific, Inc.), NRP-2 (ab129050; Abcam), Apaf-1 (ab2001; Abcam), Bad (ab32445; Abcam) for immunofluorescent staining. All antibodies were used at a dilution of 1:1,000. Cells were then incubated with goat anti-rabbit IgG H\&L (HRP) (1:2,000; ab205718; Abcam) for $1 \mathrm{~h}$ at $37^{\circ} \mathrm{C}$. All fluorescent samples were visualized with a confocal fluorescence microscope (Leica TCS SP8; Leica Corporation, Wetzlar, Germany).

Cell cycle analysis. Cells $\left(1 \times 10^{7}\right)$ were collected from the experimental mice, and fixed with $70 \%$ ethanol for $2 \mathrm{~h}$ at $30^{\circ} \mathrm{C}$. Fixed cells were rehydrated in PBS for 5 min and incubated in RNase A $\left(1 \mathrm{mg} / \mathrm{ml}\right.$ ) for $30 \mathrm{~min}$ at $37^{\circ} \mathrm{C}$. The cells were then subjected to 
A

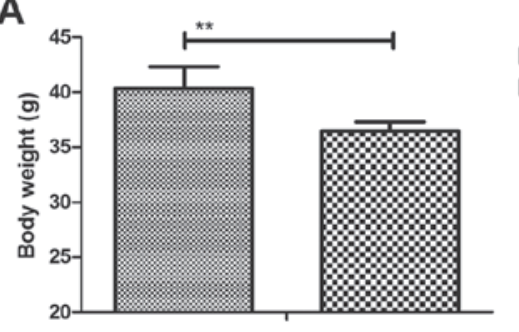

C

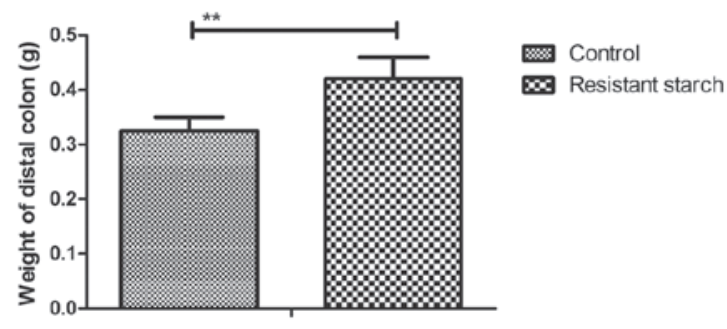

E

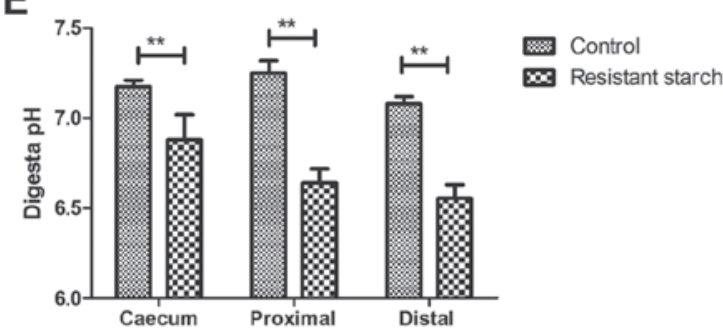

G

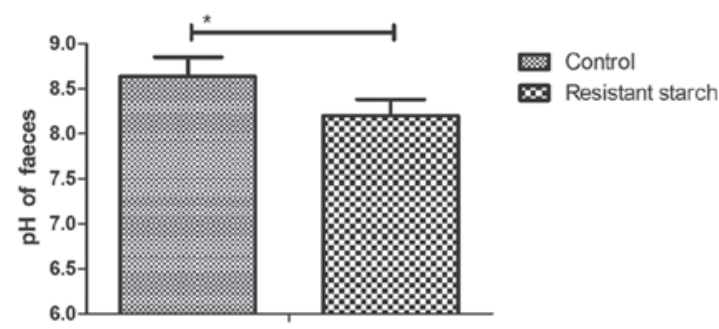

B

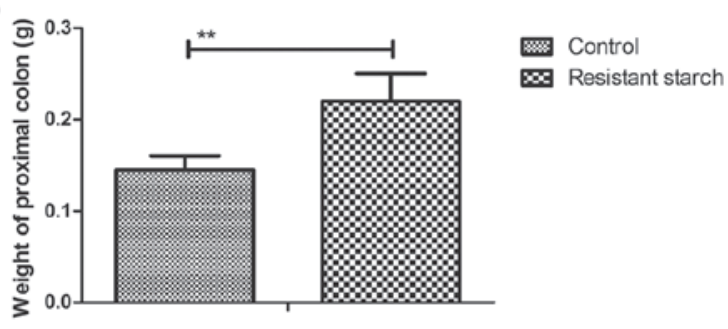

D

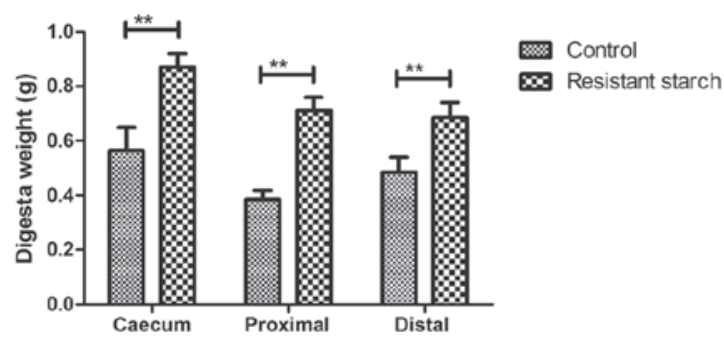

$\mathbf{F}$

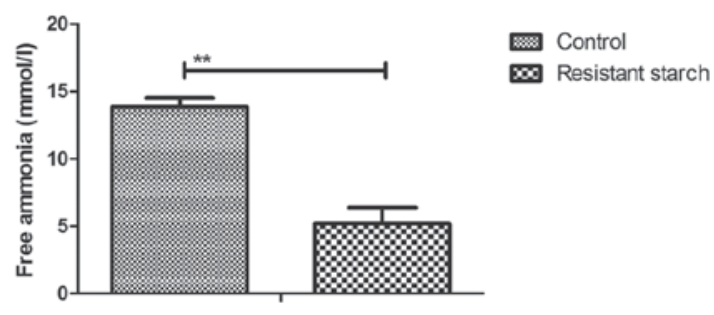

H

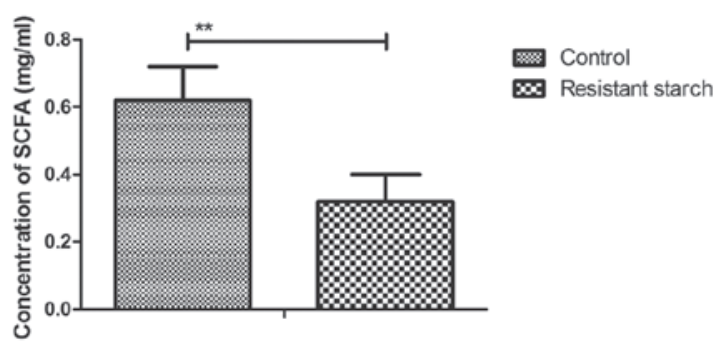

Figure 1. Effects of resistant starch on body weight and metabolic characteristic of colon tissues. (A) Body weight of experimental mice fed with resistant starch after induced by 1,2-dimethylhydrazine. Resistant starch improves weight of (B) proximal colon and (C) distal colon compared to regular diets. (D) Effects of resistant starch on digesta weight in caecum, proximal colon and distal colon in experimental mice induced by 1,2-dimethylhydrazine. (E) Digesta pH in caecum, proximal colon and distal colon in experimental mice fed with resistant starch after induced by 1,2-dimethylhydrazine. Effects of resistant starch on (F) free ammonia, (G) pH and (H) SCFA in faeces in mice fed with resistant starch. ${ }^{*} \mathrm{P}<0.05$ and ${ }^{* *} \mathrm{P}<0.01$. SCFA, short chain fatty acids.

PI/RNase staining followed by flow cytometric analysis using a FACScan instrument (Becton Dickinson, Mountain View, CA, USA) and Cell Quest software (Becton Dickinson).

Apoptosis assay. Colon tumor cells were isolated from experimental mice and trypsinized and collected for apoptosis analysis. The cells were adjusted to $5 \times 10^{6}$ cells $/ \mathrm{ml}$ with phosphate-buffered saline, labeled with Annexin V-fluorescein isothiocyanate (FITC) and propidium iodide (PI) using an Annexin V-FITC kit, and analyzed with a FACScan flow cytometer (both from BD Biosciences, Franklin Lakes, NJ,
USA). The treatments were performed in triplicate, and the percentage of labeled cells undergoing apoptosis in each group was determined and calculated using FCS Express ${ }^{\mathrm{TM}} 4$ IVD software 1.0 (De Novo Software, Glendale, CA, USA).

Statistical analysis. All data were presented as mean + standard error with three independent experiments. Statistical significance was analyzed using two tailed Student's t-test between groups. Unpaired data was analyzed by variance. $\mathrm{P}<0.05$ was considered to indicate a statistically significant difference. 
A
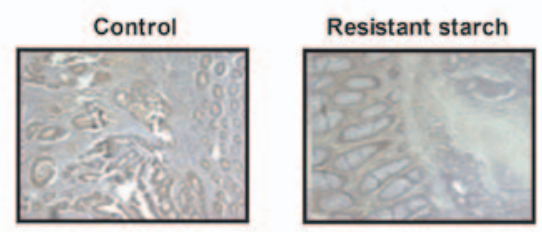

C

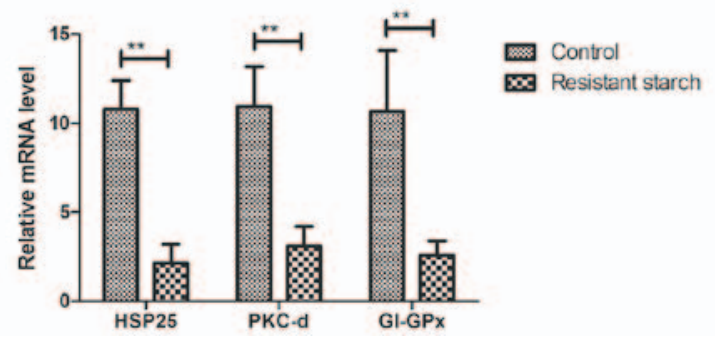

E

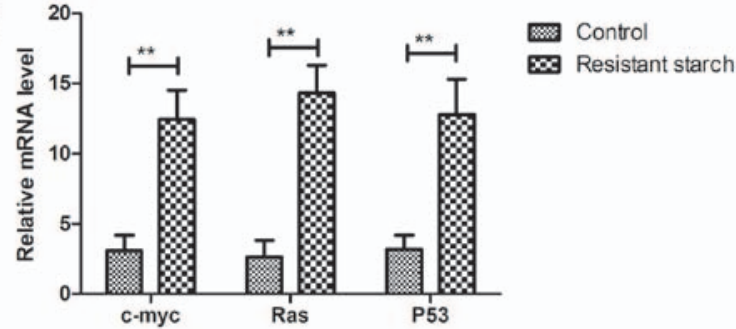

G

Microtubule

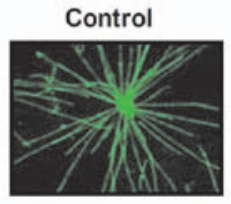

Microvascular

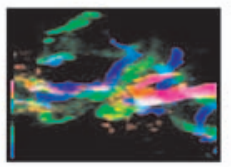

Resistant starch
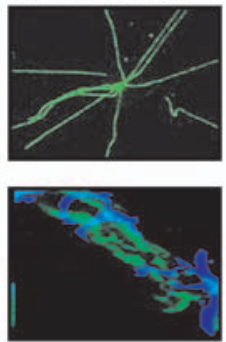

B

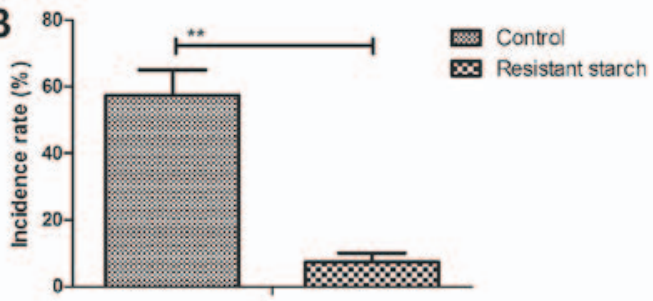

D

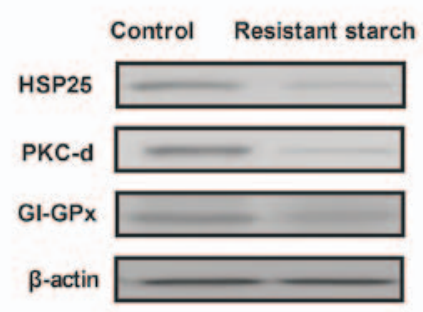

F

Control Resistant starch

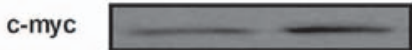

Ras

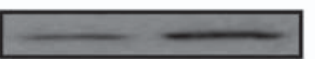

P53

$\beta$-actin

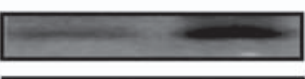

H

Control

Resistant starch
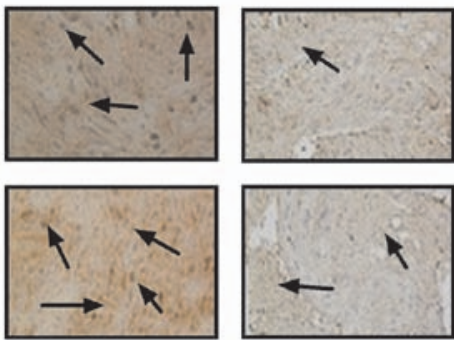

Figure 2. Effects of resistant starch on tumorigenesis in colon tissues induced by 1,2-dimethylhydrazine. (A) Resistant starch inhibits tumor formation in experimental mice treated by 1,2-dimethylhydrazine. (B) Effects of resistant starch decreases incidence of colon tumor in a mouse model induced by 1,2-dimethylhydrazine. (C) Gene and (D) protein expression levels of HSP25, PKC-d and GI-GPx in colon epithelial cells in experimental mice fed with resistant starch after induced by 1,2-dimethylhydrazine. Effects of resistant starch on (E) gene and (F) protein expression levels of c-myc, Ras and p53 in colon epithelial cells. (G) Resistant starch diet inhibits formation of microtubule and tumor vessel in colon tissues in experimental mice. (H) Resistant starch diet inhibits protein express levels of MAT-1 and NRP-2 in colon tissues in experimental mice. ${ }^{* * *} \mathrm{P}<0.01$. HSP 25 , heat shock protein 25 ; PKC-d, protein kinase C-d; GI-GPx, gastrointestinal glutathione peroxidase; MAT-1, CDK-activating kinase assembly factor MAT1; NRP-2, neuropilin-2 (magnification, x40).

\section{Results}

Resistant starch diet improves body weight and the metabolic characteristics of colon tissues. In order to investigate the benefits of resistant starch diets for metabolism of experimental mice, body weight and metabolic characteristic of colon tissues were analyzed. A resistant starch diet decreased body weight compared with a regular diet (Fig. 1A). Weight of the proximal and distal colon was also increased by resistant starch diets in experimental mice (Fig. 1B and C). The results demonstrated that digesta weight in the caecum, proximal colon and distal colon was significantly increased by the resistant starch diet compared with a regular diet (Fig. 1D). The digesta $\mathrm{pH}$ in the caecum, proximal colon and distal colon was downregulated in mice fed with resistant starch compared with a normal diet (Fig. 1E). Free ammonia, $\mathrm{pH}$ and short chain fatty acids (SCFA) in feces were decreased in mice fed with resistant starch (Fig. 1F-H). These results suggest that a resistant starch diet improves body weight and metabolic characteristics of colon tissues.

Resistant starch diet inhibits tumorigenesis in colon tissues induced by 1,2-dimethylhydrazine. Anti-tumorigenesis efficacy of resistant starch was investigated in colon tissues induced by 1,2-dimethylhydrazine. Results showed that resistant starch suppressed tumor formation in experimental mice treated by 1,2-dimethylhydrazine (Fig. 2A). Histopathology 

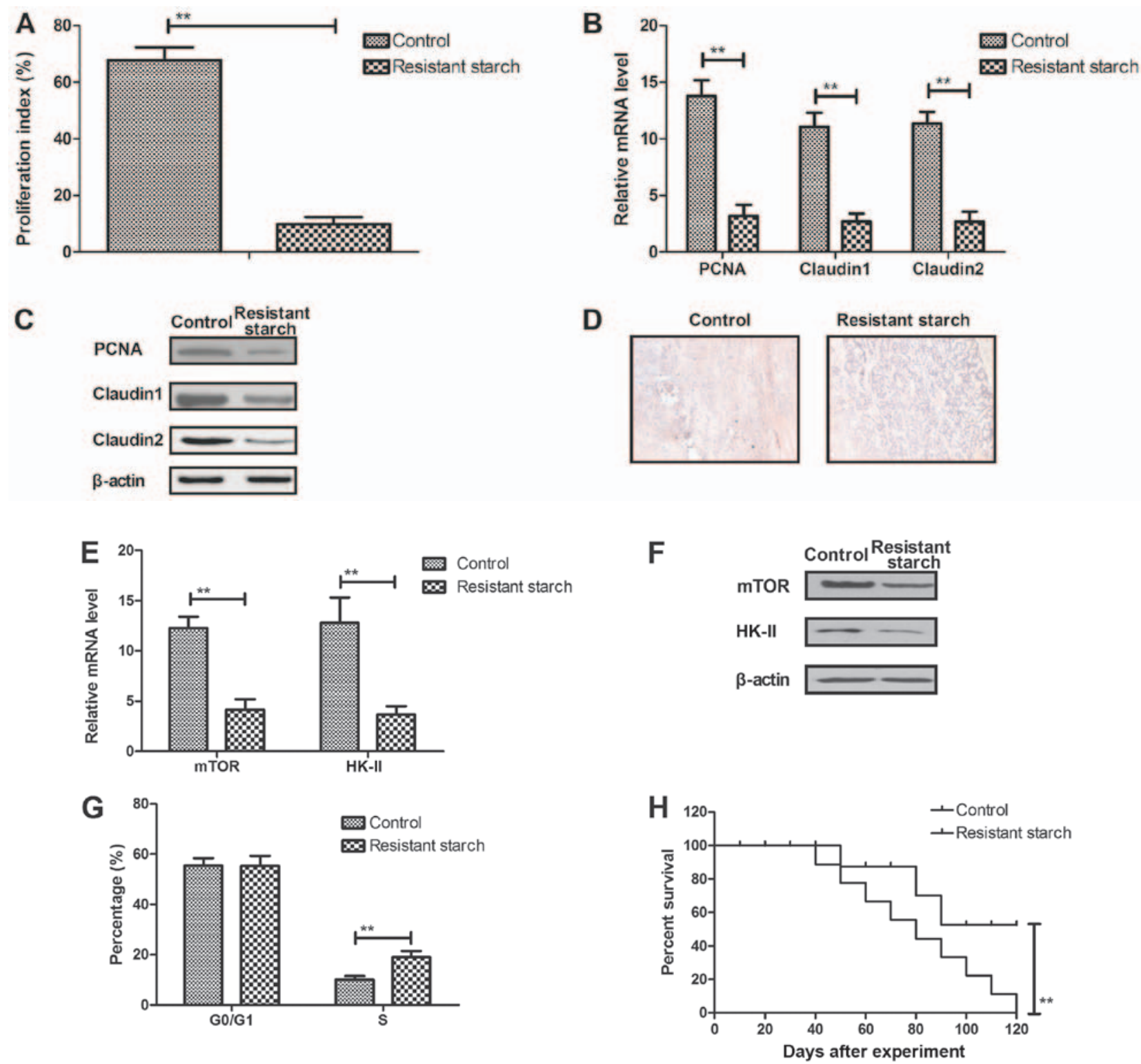

Figure 3. Effects of resistant starch on inhibition of colon tumor cells proliferation and differentiation. (A) Resistant starch diet inhibits colon tumor cells proliferation in colon tissues induced by 1,2-dimethylhydrazine. Effects of resistant starch on (B) gene and (C) protein expression levels of PCNA, claudin 1 and claudin 2 in colon tumor cells. (D) Resistant starch diet inhibits colon tumor cells differentiation in colon tissues induced by 1,2-dimethylhydrazine. Resistant starch diet blocks (E) gene and (F) protein expression levels of mTOR and HK-II in colon tumor cells. (G) Resistant starch diet arrests S phase of colon tumor cells in experimental mice. (H) Long-term survival rate of experimental mice between resistant starch diet and standard diet groups determined by Kaplan-Mrier. ${ }^{* *} \mathrm{P}<0.01$. PCNA, proliferating cell nuclear antigen; mTOR, mechanistic target of rapamycin kinase; HK-II, hexokinase-2 (magnification, $\mathrm{x} 40$ ).

demonstrated that resistant starch significantly inhibited incidence of colon tumor in mice model induced by 1,2-dimethylhydrazine (Fig. 2B). The gene and protein expression levels of carcinogenesis-associated genes, HSP25, PKC-d and GI-GPx, were downregulated in colon epithelial cells from mice receiving resistant starch compared with the standard starch group (Fig. 2C and D). However, the gene and protein expression levels of oncogenes c-myc, Ras and pro-apoptosis gene p53 were upregulated by resistant starch in colon epithelial cells (Fig. 2E and F). Immunofluorescence demonstrated that microtubule and tumor vessels were inhibited in colon tissues in mice in the resistant starch group compared with the control group (Fig. 2G). Immunohistochemistry demonstrated that the expression levels of MAT-1 and NRP-2 were downregulated by resistant starch in colon tumor tissues (Fig. 2H). These results indicated that a resistant starch diet inhibits tumorigenesis in colon tissues induced by 1,2-dimethylhydrazine.

Resistant starch diet inhibits the proliferation and differentiation of colon cells. Tumor cell proliferation and differentiation has a vital role in tumorigenesis. Thus, the effect of resistant starch on colon tumor cell proliferation and differentiation was determined. Colon tumor cell proliferation was suppressed by resistant starch compared with the control group in 1,2-dimethylhydrazine-induced mice (Fig. 3A). RT-qPCR and western blot analysis demonstrated that the expression levels of PCNA, claudin 1 and claudin 2 were decreased in colon tumor cells in resistant starch-fed mice compared with the control group (Fig. 3B and C). The results also demonstrated 

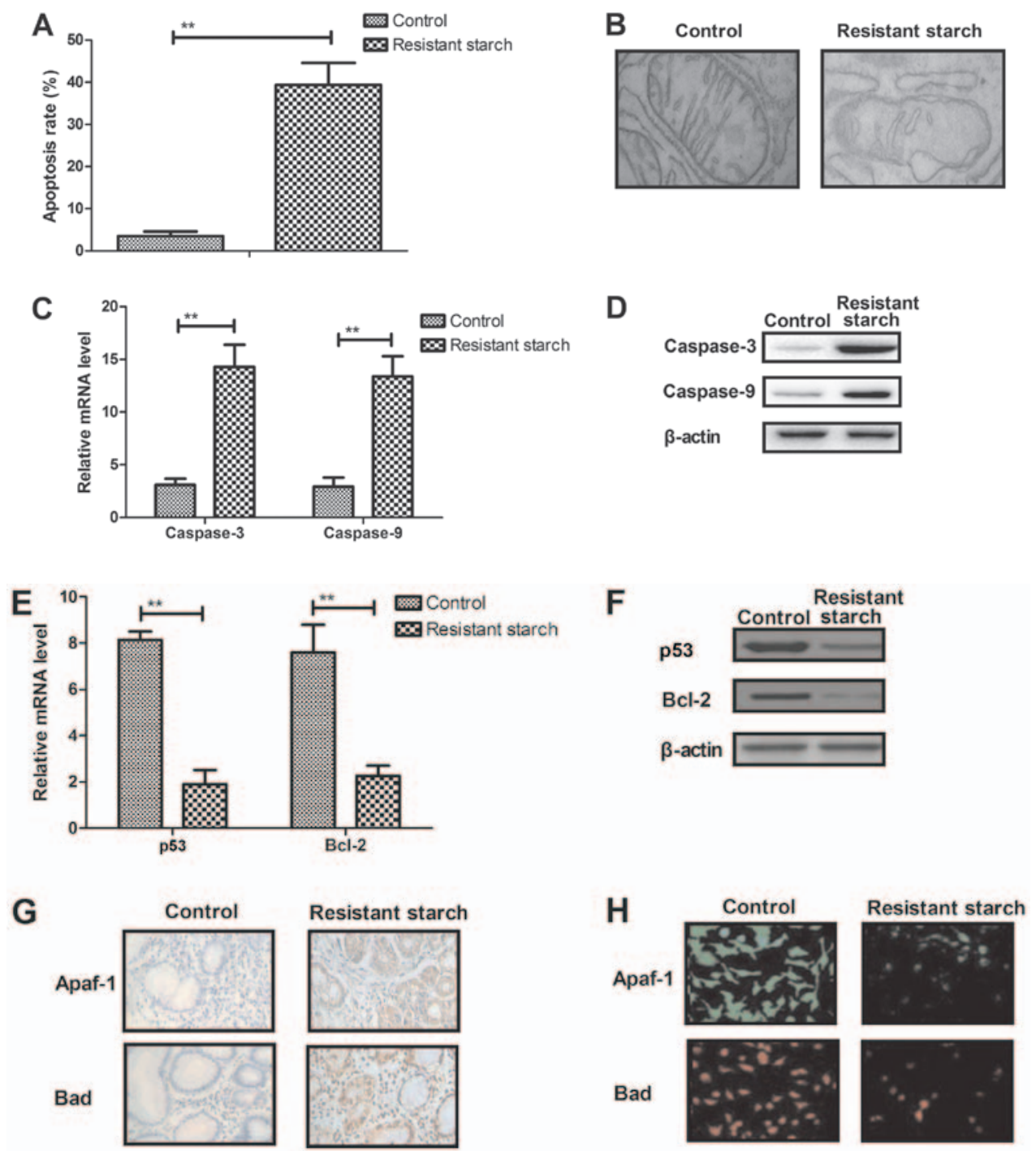

Figure 4. Resistant starch diet induces apoptosis of colon tumors through mitochondrial apoptotic pathway. (A) Resistant starch diet promotes apoptosis of colon tumor cells in mice treated by 1,2-dimethylhydrazine. (B) Effects of resistant starch diet on mitochondria damage in colon tumor cells in experimental mice (magnification, x100). Resistant starch diet increases pro-apoptosis (C) gene and (D) protein expression levels of cleaved caspase-3 and caspase-9 in colon tumor cells induced by 1,2-dimethylhydrazine. Resistant starch diet increases anti-apoptosis (E) gene and (F) protein expression levels of p53 and Bcl-2 in colon tumor cells induced by 1,2-dimethylhydrazine. Resistant starch diet promotes expression levels of Apaf-1 and Bad in colon tumor tissue in mice treated by 1,2-dimethylhydrazine determined by (G) immunohistochemistry (tissue) and (H) immunofluorescence (cells) (magnification, $\mathrm{x} 40){ }^{* * *} \mathrm{P}<0.01$. Bcl-2, apoptosis regulator Bcl-2; Apaf-1, apoptotic protease-activating factor 1; Bad, Bcl-2-associated agonist of cell death.

that resistant starch inhibited colon tumor cell differentiation in colon tissues (Fig. 3D). RT-qPCR and western blot analysis demonstrated that expression levels of mTOR and HK-II were reduced by resistant starch compared with the control diet in colon tumor cells (Fig. 3E and F). The resistant starch diet increased $\mathrm{S}$ phase arrest of colon tumor cells, and downregulation of mTOR and HK-II expression levels compared with the normal diet group (Fig. 3G). Long-term survival of experimental mice was prolonged by the inclusion of resistant starch in the diet compared with the control diet group (Fig. 3H). These results suggest that resistant starch diets can inhibit the proliferation and differentiation of colon tumor cells by arresting the cell cycle.

Resistant starch promotes apoptosis of colon tumor cells through the mitochondrial pathway. The anti-apoptosis effects of resistant starch were also analyzed in experimental mice with 1,2-dimethylhydrazine-induced colon tumors. The resistant starch diet promoted apoptosis of colon tumor cells (Fig. 4A). Cellular structure demonstrated that mitochondria exhibited different degrees of damage in colon tumor cells (Fig. 4B). Pro-apoptosis gene and protein expression levels of caspase-3 and caspase-9 were upregulated in colon tumor cells (Fig. 4C and D). However, anti-apoptosis gene and protein expression levels of p53 and $\mathrm{Bcl}-2$ were downregulated in colon tumor cells in resistant starch-fed experimental mice compared with the control treatment (Fig. 4E and F). Immunohistochemistry and immunofluorescence demonstrated that resistant starch increased Apaf-1 and Bad expression levels in colon tumor tissues in experimental mice compared with control mice (Fig. 4G and $\mathrm{H}$ ). These results suggest that resistant starch in the diet can enhance apoptosis of colon tumors through mitochondrial apoptotic pathway in mice with colon tumors induced by 1,2-dimethylhydrazine. 


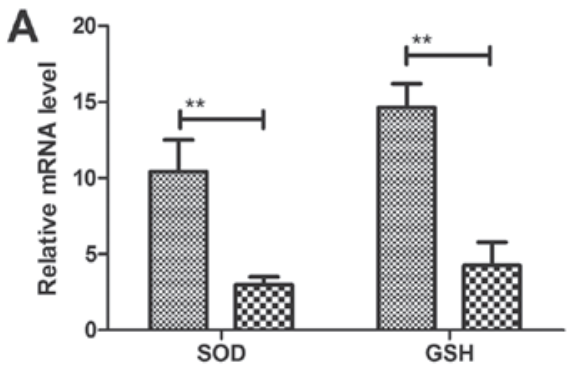

Contro

$\mathbf{\infty}$ Resistant starch

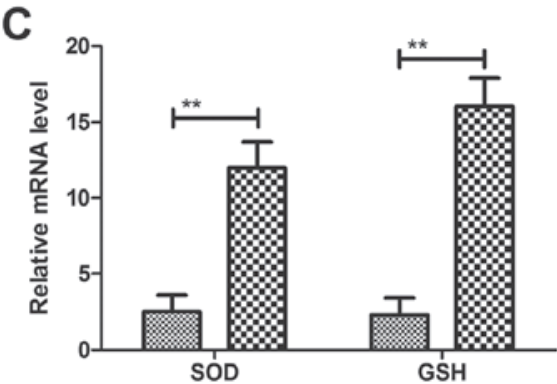

B

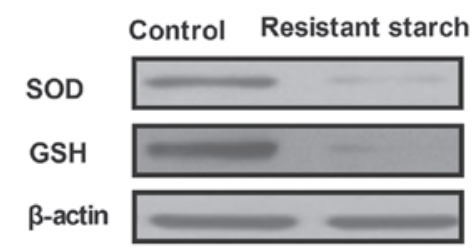

D

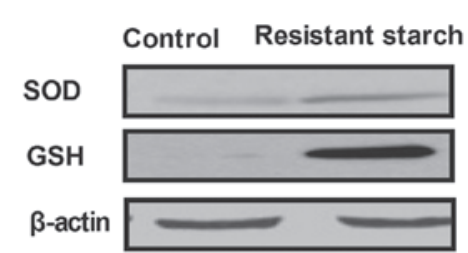

E

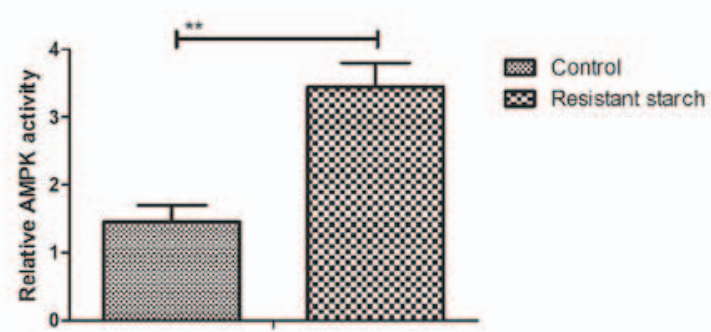

G

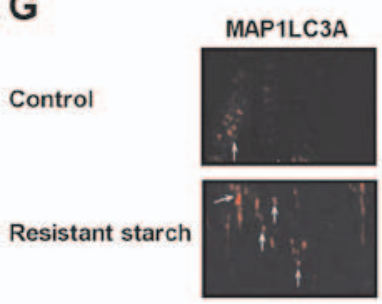

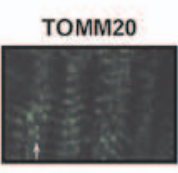

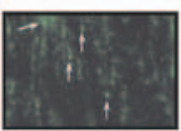

Merged
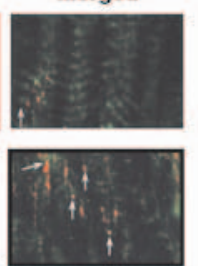

$\mathbf{F}$

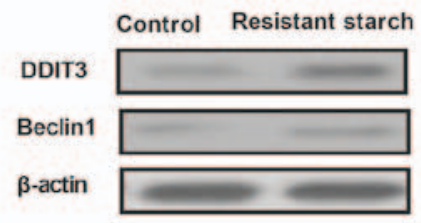

H
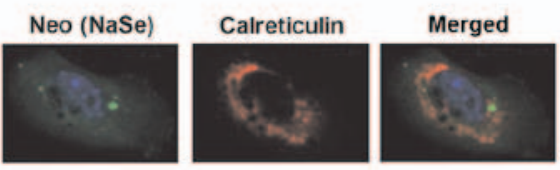

Resistant starch
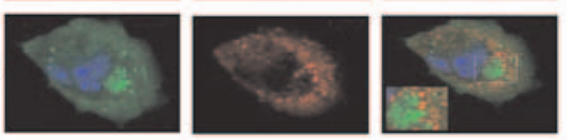

Figure 5. Resistant starch diet increases oxidative stress in colon tumors through regulation of autophagy progression. Effects of resistant starch on (A) mRNA and (B) protein levels of SOD and GSH in colon tumor cells. Effects of resistant starch on (C) mRNA and (D) protein levels of SOD and GSH in colon epithelial cells. (E) Resistant starch upregulates AMPK activity in colon tumor cells. (F) Resistant starch upregulates expression levels of DDIT3 and Beclin 1 in colon tumor cells in mice treated by 1,2-dimethylhydrazine. Resistant starch diet promotes $(\mathrm{G})$ mitophagy and (H) reticulophagy of colon tumor cells in mice treated by 1,2-dimethylhydrazine (magnification, $\mathrm{x} 40$ ). ${ }^{* *} \mathrm{P}<0.01$. SOD, superoxide dismutase; GSH, glutathione synthetase; AMPK, AMP-activated protein kinase; DDIT3, DNA damage-inducible transcript 3 protein; MAP1LC3A, microtubule associated protein 1 light chain $3 \alpha$; TOMM20, translocase of outer mitochondrial membrane 20; Neo (Nase), 5'-Nase-ALPase.

Resistant starch diet enhances oxidative stress in colon tumors through regulation of autophagy progression. Changes of oxidative stress in colon tumors and colon epithelial cells was investigated. Resistant starch diets reduced the mRNA and protein levels of SOD and GSH in colon tumor cells compared with mice that received the control diet (Fig. 5A and B). However, mRNA and protein levels of SOD and GSH were increased by resistant starch in colon epithelial cells compared to regular diet (Fig. 5C and D). AMP-activated protein kinase (AMPK) activity was increased in colon tumor cells from mice fed with resistant starch compared with the regular diet (Fig. 5E). Potential mechanisms were demonstrated as resistant starch increased the expression levels of DNA damage-inducible transcript 3 protein and Beclin 1 in colon tumor cells (Fig. 5F). The results also demonstrated that resistant starch promoted mitophagy and reticulophagy of colon tumor cells (Fig. 5G and H). Collectively, the results indicated that the resistant starch diet enhanced-activated autophagy in colon tumors through upregulation of autophagy genes.

Resistant starch diet alters ER stress-dependent PERK activity through upregulation of eIF $2 \alpha$ phosphorylation in colon tumor cells in 1,2-dimethylhydrazine-induced mice. The effect if resistant starch on ER stress and its potential mechanism in inhibition of tumor cells growth was investigated. The resistant starch diet increased the expression levels of eIF $2 \alpha$, ATF- 4 and 
A

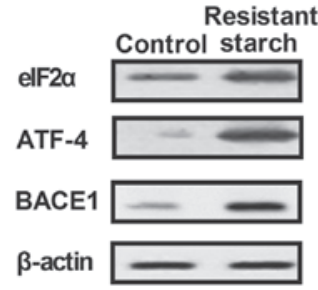

B

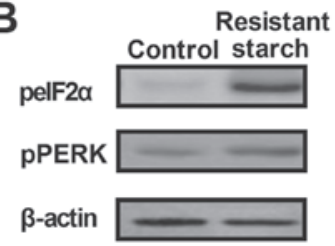

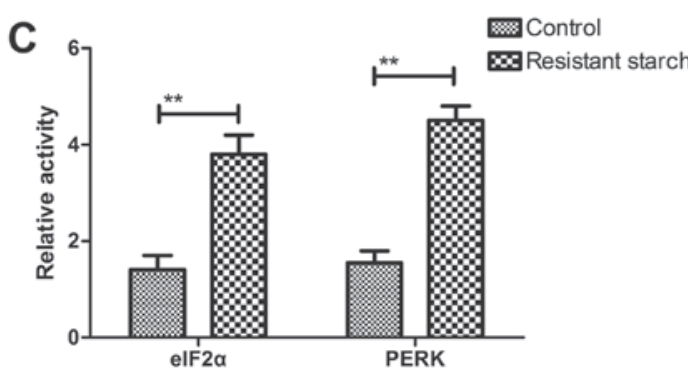

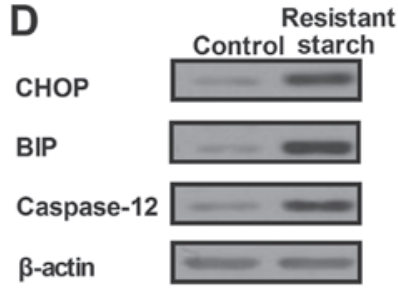

E

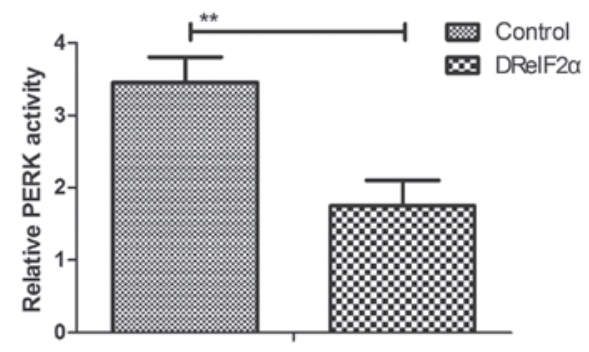

$\mathbf{F}$

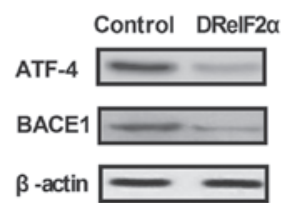

G
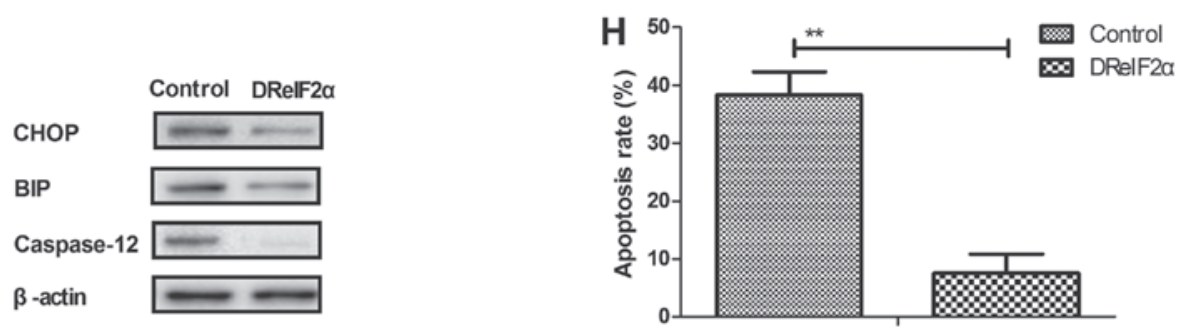

Figure 6. Resistant starch diet regulates endoplasmic reticulum stress-dependent PERK activity through upregulation of eIF2 $\alpha$ phosphorylation in colon tumor cells. (A) Resistant starch diet increases expression levels of eIF2 $\alpha$, ATF-4 and BACE1 in colon tumor cells. (B) Effects of resistant starch diet on phosphorylation levels of eIF2 $\alpha$ and PERK in colon tumor cells in mice treated by 1,2-dimethylhydrazine. (C) Effects of resistant starch diet on activity of eIF2 $\alpha$ and PERK in colon tumor cells in mice treated by 1,2-dimethylhydrazine. (D) Resistant starch diet increases expression levels of CHOP, BIP and caspase-12 in colon tumor cells in mice treated by 1,2-dimethylhydrazine. (E) Effects of DReIF2 $\alpha$ on PERK activity in colon tumor cells in mice induced by 1,2-dimethylhydrazine. (F) eIF2 $\alpha$ knockdown inhibits resistant starch-suppressed ATF-4 and BACE1 expression levels in colon tumor cells in mice fed with resistant starch. (G) Knockdown of eIF2 $\alpha$ suppresses expression levels of CHOP, BIP and caspase-12 in colon tumor cells in mice fed with resistant starch. (H) Knockdown of eIF2 $\alpha$ inhibits resistant starch-induced apoptosis of colon tumor cells isolated from mice fed with resistant starch. ${ }^{* *} \mathrm{P}<0.01$. eIF $2 \alpha$, eukaryotic translation initiation factor $2 \alpha$; ATF-4, activating transcription factor-4; BACE1, secretase- $\beta$; p, phospho; PERK, eukaryotic translation initiation factor $2-\alpha$ kinase 3 ; CHOP, DNA damage-inducible transcript 3 protein; BIP, binding immunoglobulin protein; AMPK, AMP-activated protein kinase; DReIF2 $\alpha$, downregulation of eIF2 $\alpha$.

secretase- $\beta$ (BACE1) in colon tumor cells compared with cells from control mice (Fig. 6A). Total protein expression levels of eIF2 $\alpha$ and PERK were increased by resistant starch in colon tumor cells (Fig. 6B). eIF2 $\alpha$ and PERK activity was increased by the resistant starch diet compared with the regular diet in mice induced by 1,2-dimethylhydrazine (Fig. 6C). The resistant starch diet increased the expression levels of DNA damage-inducible transcript 3 protein (CHOP), binding immunoglobulin protein (BIP) and caspase-12 in colon tumor cells (Fig. 6D). In vitro assays demonstrated that downregulation of expression levels of eIF2 $\alpha$ using siRNA suppressed PERK activity in colon tumor cells (Fig. 6E). Expression levels of ATF-4 and BACE1 were reduced by knockdown of eIF2 $\alpha$ compared with control siRNA in colon tumor cells (Fig. 6F). Knockdown of eIF2 $\alpha$ exhibited inhibitory effects on CHOP, BIP and caspase-12 expression in colon tumor cells isolated from mice fed by resistant starch (Fig. 6G). Result also demonstrated that knockdown of eIF2 $\alpha$ inhibited resistant starch-induced apoptosis of colon tumor cells (Fig. 6H). Collectively, these results suggest that the resistant starch diet regulated ER stress-dependent PERK activity through upregulation of eIF2 $\alpha$ activity in colon tumor cells in mice induced by 1,2-dimethylhydrazine.

\section{Discussion}

Colon cancer is one of the most common gastrointestinal tumors, with highly invasive ability characterized by rapid invasion of lymphatics, flow transfer and local 
invasion (29,30). Various studies have indicated that most cases of sporadic colon cancer can be attributed to diet $(31,32)$. Studies have suggested that resistant starch fermentation modulated colonic bacterial metabolism and reduced the risk of colon cancer tumorigenesis (33). The current study investigated the benefits and potential mechanism of resistant starch-mediated anti-cancer efficacy in experimental mice induced by 1,2-dimethylhydrazine. Compared with a regular diet, the resistant starch diet inhibited tumorigenesis, proliferation and differentiation in colon tissues induced by 1,2-dimethylhydrazine, and increased the animal body weight and improved the metabolic characteristics of the colon tissues. Analysis of the molecular mechanisms indicated that the resistant starch diet promotedapoptosis of colon tumor cells through the mitochondrial apoptotic pathway, enhanced oxidative stress through regulation of autophagy progression, and regulated ER stress-dependent PERK activity through upregulation of eIF $2 \alpha$ activity in the colon tumor cells of mice induced by 1,2-dimethylhydrazine.

Tumorigenesis mechanisms are crucial for initiation and progression of tumor formation (34). Previous studies have reported that elevation of mRNA expression levels of PKC-d, HSP25 and GI-GPx are associated with tumorigenesis (35). The resistant starch diet downregulated expression levels of PKC-d, HSP25 and GI-GPx in colon epithelial cells that contributed to inhibition of tumor lesions formation. Studies have clearly demonstrated that tumor blood vessels and higher expression levels of MAT-1 and NRP-2 hindered the therapeutic efficacy of anti-cancer drugs (36-38). The data of the current study revealed that the structure of microtubules and tumor vessels in colon tumor cells were altered and gene expression of MAT-1 and NRP-2 were downregulated in resistant starch-fed mice induced by 1,2-dimethylhydrazine.

Proliferation and differentiation of colon tumor cells contribute to tumor migration and invasion mediated by molecular signaling through effector pathways (39). In the present study, the resistant starch diet inhibited proliferation and differentiation of colon tumor cells by decreasing PCNA, claudin 1 and claudin 2 gene and protein expression levels. The results also indicated that resistant starch arrested the cell cycle of colon tumor cells and downregulated mTOR and HK-II expression levels, which may have contributed to the increased long-term survival of experimental mice in the resistant starch group compared with the control diet group.

Induction of apoptosis by tumor therapeutic agents is essential for cancer therapy (40). In this study, the anti-cancer efficacy of resistant starch was investigated in mice induced with 1,2-dimethylhydrazine. The results demonstrated that resistant starch promoted apoptosis via the mitochondrial apoptotic pathway, and also increased the expression of tumor suppressor genes in colon epithelial cells. These results suggest that resistant starch contributes to apoptosis of colon tumor cells and anti-apoptosis efficacy of colon epithelial cells in experimental mice induced by 1,2-dimethylhydrazine. However, we observed that p53 was reduced by resistant starch, which is one of the most important tumor suppressor gene. Therefore, further study should perform to identify the inhibitory effects of resistant starch on tumor cells. Additionally, we found that oncogenes c-myc and Ras were upregulated by resistant starch, which also need to further analyzed in our future work.
Autophagy is a cellular progression of materials conversion that promotes the obliteration of metabolic precursors $(41,42)$. A previous study demonstrated that autophagy contributes to the inhibition of oncogenesis and suppression of tumor growth in colon cancer (43). Jang et al (44) reported that promotion of autophagy can inhibit tumorigenesis and induce apoptosis of human cancer cells by modulating sphingolipids, and suppress colon tumor development in mice. In the current study, the resistant starch diet increased oxidative stress and increased SOD and GSH levels in colon tumors. AMPK activity, mitophagy, reticulophagy and Beclin 1 expression were also increased by resistant starch in colon tumor cells $(45,46)$.

Studies have indicated that ER stress is associated with apoptosis of colon tumor cells (47). PERK activation has an important role in promoting tumorigenesis by attenuating apoptosis of premalignant granule cell precursors (48). The current study demonstrated that the resistant starch diet promoted the expression levels of eIF $2 \alpha$, ATF-4 and BACE1, and increased eIF $2 \alpha$ activity in colon tumor cells. Mechanistic analysis indicated that knockdown of eIF2 $\alpha$ exhibited inhibitory effects on CHOP, BIP and caspase-12 expression, and apoptosis in colon tumor cells isolated from mice fed with the resistant starch diet. The results of the present study indicated that the resistant starch diet promoted apoptosis by regulating ER stress-dependent PERK activity via upregulation of eIF2 $\alpha$ activity in colon tumor cells from mice induced by 1,2-dimethylhydrazine, which contributes to tumor suppression.

In conclusion, resistant starch improved bowel function, and the outcomes indicated that the resistant starch diet improved body weight and the metabolic characteristic of colon tissues. The results indicated that resistant starch inhibited tumorigenesis in the colon by promoting apoptosis and autophagy by upregulation of ER stress-dependent PERK activity, which mediated by eIF $2 \alpha$ in colon tumor cells from mice induced by 1,2-dimethylhydrazine. These investigations indicated that resistant starch prevents tumorigenesis of colon tumors induced by dimethylhydrazine via regulation of an ER stress-mediated mitochondrial apoptosis pathway, which may useful in the future for the prevention of tumorigenesis of colon tissues.

\section{Competing interests}

The authors declare that they have no competing interests.

\section{References}

1. Lopez NE, Weiss AC, Robles J, Fanta P and Ramamoorthy SL: A systematic review of clinically available gene expression profiling assays for stage II colorectal cancer: Initial steps toward genetic staging. Am J Surg 212: 700-714, 2016.

2. Burness CB and Duggan ST: Trifluridine/tipiracil: A review in metastatic colorectal cancer. Drugs 76: 1393-1402, 2016.

3. Moriarity A, O'Sullivan J, Kennedy J, Mehigan B and McCormick P: Current targeted therapies in the treatment of advanced colorectal cancer: A review. Ther Adv Med Oncol 8: 276-293, 2016

4. Chibaudel B, Bonnetain F, Tournigand C and de Gramont A: Maintenance treatment in metastatic colorectal cancer. Lancet Oncol 16: e583-e584, 2015.

5. Moilanen JM, Kokkonen N, Löffek S, Väyrynen JP, Syväniemi E, Hurskainen T, Mäkinen M, Klintrup K, Mäkelä J, Sormunen R, et al: Collagen XVII expression correlates with the invasion and metastasis of colorectal cancer. Hum Pathol 46: 434-442, 2015. 
6. Fan Z, Cui H, Xu X, Lin Z, Zhang X, Kang L, Han B, Meng J, Yan Z, Yan X, et al: MiR-125a suppresses tumor growth, invasion and metastasis in cervical cancer by targeting STAT3. Oncotarget 6: 25266-25280, 2015

7. Zhang XB, Song L, Wen HJ, Bai XX, Li ZJ and Ma LJ: Upregulation of microRNA-31 targeting integrin alpha5 suppresses tumor cell invasion and metastasis by indirectly regulating PI3K/AKT pathway in human gastric cancer SGC7901 cells. Tumour Biol 37: 8317-8325, 2016.

8. Guo J, Yu X, Gu J, Lin Z, Zhao G, Xu F, Lu C and Ge D: Regulation of CXCR4/AKT-signaling-induced cell invasion and tumor metastasis by RhoA, Rac-1, and $\mathrm{Cdc} 42$ in human esophageal cancer. Tumour Biol 37: 6371-6378, 2016.

9. Jiang N, Deng JY, Liu Y, Ke B, Liu HG and Liang H: Incorporation of perineural invasion of gastric carcinoma into the 7 th edition tumor-node-metastasis staging system. Tumour Biol 35: 9429-9436, 2014

10. Bukurova IuA, Khankin SL, Krasnov GS, Grigor'eva ES Mashkova TD, Lisitsin NA, Karpov VL and Beresten' SF: Comparison of 2D analysis and bioinformatics search efficiency for colon cancer marker identification. Mol Biol (Mosk) 44: 375-381, 2010 (In Russian).

11. Thompson BA, Goldgar DE, Paterson C, Clendenning M, Walters R, Arnold S, Parsons MT, Michael D W, Gallinger S, Haile RW, et al; Colon Cancer Family Registry: A multifactorial likelihood model for MMR gene variant classification incorporating probabilities based on sequence bioinformatics and tumor characteristics: A report from the Colon Cancer Family Registry. Hum Mutat 34: 200-209, 2013.

12. Ma Z and Boye JI: Research advances on structural characterization of resistant starch and its structure-physiological function relationship: A review. Crit Rev Food Sci Nutr: Sep 19, 2016 (Epub ahead of print). doi: 10.1080/10408398.2016.1230537.

13. Raigond P, Ezekiel R and Raigond B: Resistant starch in food: A review. J Sci Food Agric 95: 1968-1978, 2015.

14. Shen D, Bai H, Li Z, Yu Y, Zhang H and Chen L: Positive effects of resistant starch supplementation on bowel function in healthy adults: A systematic review and meta-analysis of randomized controlled trials. Int J Food Sci Nutr 68: 149-157, 2017.

15. Dronamraju SS, Coxhead JM, Kelly SB, Burn J and Mathers JC: Cell kinetics and gene expression changes in colorectal cancer patients given resistant starch: A randomised controlled trial. Gut 58: 413-420, 2009.

16. Le Leu RK, Hu Y, Brown IL, Woodman RJ and Young GP Synbiotic intervention of Bifidobacterium lactis and resistant starch protects against colorectal cancer development in rats. Carcinogenesis 31: 246-251, 2010.

17. Mathers JC, Movahedi M, Macrae F, Mecklin JP, Moeslein G, Olschwang S, Eccles D, Evans G, Maher ER, Bertario L, et al; CAPP2 Investigators: Long-term effect of resistant starch on cancer risk in carriers of hereditary colorectal cancer: An analysis from the CAPP2 randomised controlled trial. Lancet Oncol 13: 1242-1249, 2012

18. Lee JS, Jung WK, Jeong MH, Yoon TR and Kim HK: Sanguinarine induces apoptosis of HT-29 human colon cancer cells via the regulation of $\mathrm{Bax} / \mathrm{Bcl}-2$ ratio and caspase-9-dependent pathway. Int J Toxicol 31: 70-77, 2012

19. Crespo I, San-Miguel B, Prause C, Marroni N, Cuevas MJ, González-Gallego J and Tuñón MJ: Glutamine treatment attenuates endoplasmic reticulum stress and apoptosis in TNBS-induced colitis. PLoS One 7: e50407, 2012.

20. Wali VB, Bachawal SV and Sylvester PW: Endoplasmic reticulum stress mediates gamma-tocotrienol-induced apoptosis in mammary tumor cells. Apoptosis 14: 1366-1377, 2009.

21. Edagawa M, Kawauchi J, Hirata M, Goshima H, Inoue M, Okamoto T, Murakami A, Maehara Y and Kitajima S: Role of activating transcription factor 3 (ATF3) in endoplasmic reticulum (ER) stress-induced sensitization of p53-deficien human colon cancer cells to tumor necrosis factor (TNF)-related apoptosis-inducing ligand (TRAIL)-mediated apoptosis through upregulation of death receptor 5 (DR5) by zerumbone and celecoxib. J Biol Chem 289: 21544-21561, 2014.

22. Hawkins P, Morton DB, Burman O, Dennison N, Honess P, Jennings M, Lane S, Middleton V, Roughan JV, Wells S, et al: A guide to defining and implementing protocols for the welfare assessment of laboratory animals: eleventh report of the BVAAWF/FRAME/RSPCA/UFAW Joint Working Group on Refinement. Lab Anim 45: 1-13, 2011

23. Xiao S, Wang J and Xiao N: MicroRNAs as noninvasive biomarkers in bladder cancer detection: a diagnostic meta-analysis based on qRT-PCR data. Int J Biol Markers 31: e276-e285, 2016.
24. Livak and Schmittgen: Analysis of relative gene expression data using real-time quantitative PCR and the $2-\Delta \Delta \mathrm{Ct}$ method. Methods 25: 402-408, 2001.

25. Atkins C, Liu Q, Minthorn E, Zhang SY, Figueroa DJ, Moss K, Stanley TB, Sanders B, Goetz A, Gaul N, et al: Characterization of a novel PERK kinase inhibitor with antitumor and antiangiogenic activity. Cancer Res 73: 1993-2002, 2013.

26. Chaveroux C, Carraro V, Canaple L, Averous J, Maurin AC, Jousse C, Muranishi Y, Parry L, Mesclon F, Gatti E, et al: In vivo imaging of the spatiotemporal activity of the eIF2 $\alpha$-ATF4 signaling pathway: Insights into stress and related disorders. Sci Signal 8: rs5, 2015.

27. Yuan W, Ahmad S and Najar A: Morin, a plant derived flavonoid, modulates the expression of peroxisome proliferator-activated receptor-gamma coactivator-1alpha mediated by AMPK pathway in hepatic stellate cells. Am J Translat Res 9: 5662-5670, 2017.

28. Christova I: Enzyme-linked immunosorbent assay, immunofluorescent assay, and recombinant immunoblotting in the serodiagnosis of early Lyme borreliosis. Int J Immunopathol Pharmacol 16: 261-268, 2003

29. Yamaoka Y, Yamaguchi T, Kinugasa Y, Shiomi A, Kagawa H, Yamakawa Y, Numata M, Sugimoto S, Imai K, Hotta K, et al: Adenocarcinoma arising from jejunal ectopic pancreas mimicking peritoneal metastasis from colon cancer: a case report and literature review. Surg Case Rep 1: 114, 2015.

30. Hirai HW, Tsoi KK, Chan JY, Wong SH, Ching JY, Wong MC, Wu JC, Chan FK, Sung JJ and Ng SC: Systematic review with meta-analysis: Faecal occult blood tests show lower colorectal cancer detection rates in the proximal colon in colonoscopy-verified diagnostic studies. Aliment Pharmacol Ther 43: 755-764, 2016.

31. Birt DF and Phillips GJ: Diet, genes, and microbes: Complexities of colon cancer prevention. Toxicol Pathol 42: 182-188, 2014.

32. Ou J, Carbonero F, Zoetendal EG, DeLany JP, Wang M, Newton K, Gaskins HR and O'Keefe SJ: Diet, microbiota, and microbial metabolites in colon cancer risk in rural Africans and African Americans. Am J Clin Nutr 98: 111-120, 2013.

33. Ridlon JM and Hylemon PB: A potential role for resistant starch fermentation in modulating colonic bacterial metabolism and colon cancer risk. Cancer Biol Ther 5: 273-274, 2006.

34. Yueh AE, Payne SN, Leystra AA, Van De Hey DR, Foley TM, Pasch CA, Clipson L, Matkowskyj KA and Deming DA: Colon cancer tumorigenesis initiated by the H1047R mutant PI3K. PLoS One 11: e0148730, 2016.

35. Zhang C, Qu S, Wei X, Feng Y, Zhu H, Deng J, Wang K, Liu K, Liu M, Zhang H, et al: HSP25 downregulation enhanced p53 acetylation by dissociation of SIRT1 from p53 in doxorubicin-induced H9c2 cell apoptosis. Cell Stress Chaperones 21: 251-260, 2016.

36. Molinari AJ, Pozzi EC, Monti Hughes A, Heber EM, Garabalino MA, Thorp SI, Miller M, Itoiz ME, Aromando RF, Nigg DW, et al: Tumor blood vessel 'normalization' improves the therapeutic efficacy of boron neutron capture therapy (BNCT) in experimental oral cancer. Radiat Res 177: 59-68, 2012.

37. Marín M, Muskus C, Ramírez JR, Arbelaez LF, Alzate JF and Berberich C: The gene encoding the metacyclogenesis-associated transcript Mat-1 is conserved in the genus Leishmania and shows a tendency to form dimers upon protein expression. Parasitol Res 86: 431-435, 2000

38. Stanton MJ, Dutta S, Zhang H, Polavaram NS, Leontovich AA, Hönscheid P, Sinicrope FA, Tindall DJ, Muders MH and Datta K: Autophagy control by the VEGF-C/NRP-2 axis in cancer and its implication for treatment resistance. Cancer Res 73: 160-171, 2013.

39. Haigis KM, Kendall KR, Wang Y, Cheung A, Haigis MC, Glickman JN, Niwa-Kawakita M, Sweet-Cordero A, Sebolt-Leopold J, Shannon KM, et al: Differential effects of oncogenic K-Ras and N-Ras on proliferation, differentiation and tumor progression in the colon. Nat Genet 40: 600-608, 2008.

40. Hino M, Ichihara H, Matsumoto $\mathrm{Y}$ and Ueoka R: Anti-tumor effects of cationic hybrid liposomes against colon carcinoma along with apoptosis in vitro. Biol Pharm Bull 35: 2097-2101, 2012 .

41. Nabizadeh A, Bamdad T, Arefian E and Razavi Nikoo SH: Autophagy gene activity may act as a key factor for sensitivity of tumor cells to oncolytic vesicular stomatitis virus. Iran J Cancer Prev 9: e3919, 2016.

42. Dagistanli FK, Ozkaya HM, Kucukyoruk B, Biceroglu H, Metin D, Gazioglu N, Oz B, Kadioglu P and Ozturk M: Preoperative somatostatin analogue treatment might trigger apoptosis and autophagy in tumor tissues of patients with acromegaly: A pilot study. Exp Clin Endocrinol Diabetes: Jun 20, 2016 (Epub ahead of print). doi: 10.1055/s-0042-107243. 
43. Zhai $\mathrm{H}$, Song $\mathrm{B}, \mathrm{Xu} \mathrm{X}$, Zhu W and Ju J: Inhibition of autophagy and tumor growth in colon cancer by miR-502. Oncogene 32: $1570-1579,2013$

44. Jang Y, Park NY, Rostgaard-Hansen AL, Huang J and Jiang Q: Vitamin E metabolite 13'-carboxychromanols inhibit pro-inflammatory enzymes, induce apoptosis and autophagy in human cancer cells by modulating sphingolipids and suppress colon tumor development in mice. Free Radic Biol Med 95: 190-199, 2016.

45. Baskaran R, Poornima P, Priya LB, Huang CY and Padma VV: Neferine prevents autophagy induced by hypoxia through activation of Akt/mTOR pathway and Nrf2 in muscle cells. Biomed Pharmacother 83: 1407-1413, 2016.

46. Liu W, Shang G, Yang S, Huang J, Xue X, Lin Y, Zheng Y, Wang X, Wang L, Lin R, et al: Electroacupuncture protects against ischemic stroke by reducing autophagosome formation and inhibiting autophagy through the mTORC1-ULK1 complex-Beclin1 pathway. Int J Mol Med 37: 309-318, 2016.
47. Khan I, Paul S, Jakhar R, Bhardwaj M, Han J and Kang SC: Novel quercetin derivative TEF induces ER stress and mitochondria-mediated apoptosis in human colon cancer HCT-116 cells. Biomed Pharmacother 84: 789-799, 2016.

48. Ho Y, Li X, Jamison S, Harding HP, McKinnon PJ, Ron D and Lin W: PERK activation promotes medulloblastoma tumorigenesis by attenuating premalignant granule cell precursor apoptosis. Am J Pathol 186: 1939-1951, 2016.

This work is licensed under a Creative Commons Attribution-NonCommercial-NoDerivatives 4.0 International (CC BY-NC-ND 4.0) License. 